\title{
Adaptation of Agricultural and Food Systems to a Changing Climate and Increasing Urbanization
}

\author{
Maurice Pitesky • Amrith Gunasekara • Carolyn Cook • \\ Frank Mitloehner
}

Published online: 7 March 2014

(C) Springer International Publishing AG 2014

\begin{abstract}
Climate change will pose risks for the world's food supply in the coming decades; this comes at a time when the global demand for food is expected to soar based on 2050 world population estimates. It is important to recognize that climate change will necessitate temporal and geographical shifts in food production, but will most likely not result in the collapse of our food systems. However, because of differences in the severity of how climate change will affect agriculture, regional and temporal changes in production and harvest-time will challenge the existing and sometimes outdated agricultural infrastructure with respect to collection, storage, transportation, and distribution of food. Increasing regional and global urbanization will further perturb these systems. Adaptation to climate change with respect to crop and food animal production will have to occur at multiple temporal, seasonal, and geospatial levels. Other major adaptation measures will have to occur with respect to crop selection, genetics, $\mathrm{CO}_{2}$ and temperature sensitivity, and resilience of crops and food animals, water resources, and mitigation of
\end{abstract}

\author{
M. Pitesky \\ UC Davis School of Veterinary Medicine, University of California, \\ Davis, CA, USA \\ e-mail: mepitesky@ucdavis.edu \\ A. Gunasekara \\ California Department of Food and Agriculture, Sacramento, CA, \\ USA \\ e-mail: Amrith.Gunasekara@cdfa.ca.gov \\ C. Cook \\ California Department of Food and Agriculture, Division of Plant \\ Health and Pest Prevention Services, Sacramento, CA, USA \\ e-mail: Carolyn.Cook@cdfa.ca.gov \\ F. Mitloehner ( $\varangle)$ \\ Department of Animal Science, University of California, 2151 \\ Meyer Hall, One Shields Ave, Davis, CA 95616, USA \\ e-mail: fmmitloehner@ucdavis.edu
}

invasive species. Technology, including sophisticated Geographic Information Systems (GIS)-based modeling, coupled with publically available soil and weather data that help farmers optimize production and conservation will be essential toward adaptation. Communication of this type of localized technical information to agricultural stakeholders by national, federal, and state entities is beginning to occur in order to help farmers adapt and prepare for extreme events associated with climate change. As the largest agricultural state in the USA, California has developed a robust mitigation and adaptation strategy that may be useful for other nation-states.

Keywords Climate change - Crop adaptation - Food animal adaptation $\cdot$ Pollinators $\cdot$ Phenology

\section{Understanding the Significance of Climate Change and Agriculture}

Climate change will have variable impacts on agriculture based on multiple factors including changes in temperature, precipitation, and humidity. The magnitude and significance of these changes will be dependent on geography (e.g., summer temperatures will increase more in southern Europe, while winter temperatures will increase more in northern Europe) [1]. These abiotic changes will select for different biotic organisms from micro-organisms to insects, to plants and livestock and poultry. Such changes are already affecting our current agricultural production systems. For example, increases in temperature in California's Central Valley $[2,3]$ and a corresponding loss of winter chill hours associated with temperature increases $[4,5]$ will lead to inhomogeneous and reduced crop yields for several major tree fruit crops [6 ${ }^{\bullet}$.

A second example of the impact of climate change is phenology (i.e., seasonal timing) and the potential for phenological mismatches (i.e., shift in phenologies that negatively 
affect an interaction) [7]. Because climate is one of the major factors that affect habitat and carrying capacity, it can therefore have different impacts on the spatial and temporal distribution of animals and plants that have an agriculturally significant symbiotic relationship. For example, warmer spring temperatures could shift wild bee population dynamics out of synchrony with plant development, thereby reducing the potential for bee nutrition, plant pollination, and fruit production [8]. These same phenological mismatch scenarios exist for herbivorous migratory livestock [9]. Globally, foraging livestock are an important source of protein and fertilizer. Therefore, these types of phenological mismatches could have significant effects on food security and even urbanization in that "traditional" farming techniques may no longer be viable or may require increased resources. For example, globally, increased acreage is allocated to producing pollinatordependent crops; this is an input that may increase costs for farmers [10].

Production and welfare of food animals (i.e., livestock, poultry, and fish) will also be affected in several different ways. Insects are ectotherms, and therefore temperature is a major factor in reproduction. An increase in the temperature of $2^{\circ} \mathrm{C}$ could result in up to five additional insect life cycles per season [11]. Changes in climate and humidity in northern Europe over the last 30 years have created a favorable habitat for certain insects that can be vectors for disease in humans or livestock [12]. For example, vector-borne diseases such as the Blue tongue and Schmallenberg viruses have recently affected the morbidity and mortality of livestock in northern latitudes due to the northern expansion of the biting midge Culicoides that, historically, has been limited to tropical and subtropical areas of the world [12, 13]. In addition to the introduction of new diseases, climate change could have a negative impact on production efficiency with respect to feed conversion ratios for meat, milk, and egg production $[14,15]$. For example, a 1week long heat wave in California in 2006 was responsible for the deaths of more than 30,000 dairy cows. In addition, as a consequence of the heat wave, milk production dropped by more than $20 \%$. Finally, in the oceans, climate change is expected to shift water temperature, salinity, ocean acidity, and water column structure, resulting in habitat shifts to different latitudes and deeper waters [16].

A less-explored area of climate change with respect to agriculture is the effect of increased urbanization on the agricultural sector. Historically, increased crop yields have helped facilitate urbanization. However, increased urbanization increases the dependence of consumers on food importation. With increasing urbanization and geographical shifts in urbanization in the developing world, demand for food will increase in Sub-Saharan Africa and Asia. The distribution of this food to densely populated areas will strain existing transportation systems. This shift could lead to increased food wastage due to the lack of infrastructure noted.

\section{What is Adaptation and How Does it Differ from Mitigation?}

Because agriculture and climate are so inherently linked, multiple strategies are being considered and adopted by stakeholders. Mitigation involves reducing the overall significance of climate change primarily via emissions reductions and/or retention of agricultural land as opposed to conversion to urban land (a recent study showed that urban land use in Yolo County in California had average emissions of more than 70 times that of irrigated cropland [17]). In contrast, adaptation involves efforts to limit our vulnerability to the effects of climate change without necessarily addressing the underlying cause [18]. Figure 1 shows potential seasonal adaptations for crops and generic adaptations for food animals. It is important to recognize that adaptation scenarios are usually focused on modifying a particular crop or controlling a pest versus addressing an entire ecosystem, which can be a counterproductive approach because of the inherent complexity of each system. However, one advantage of adaptation is that adaptive changes can typically be made independent of government as opposed to mitigation which often requires regulatory mandates (e.g., carbon tax and/or cap and trade system) for widescale adoption. That being said, an overall strategy that involves both mitigation and adaptation appears to have the greatest potential toward reducing climate change vulnerability [19]. In reality, large agriculture production states, such as California, are already doing both. For example, California is in the process of updating its adaptation plan titled "Safeguarding California: Reducing Climate Risk," as well as a research plan and a climate change mitigation plan titled the "Climate Change Scoping Plan Update." As part of the state mitigation efforts, a cap and trade system has been designed and implemented to reduce California's total anthropogenic greenhouse gas (GHG) emissions to 1990 levels by 2020. Water conservation and other voluntary agricultural efforts are already occurring through the deployment of high-tech irrigation systems and improved grower knowledge about evapotranspiration (ET) and soil moisture management.

It is important to recognize that adaptation doesn't come without consequences. Competing goals need to be studied and considered; when adaptation decisions are made, there may be negative tradeoffs. For example, creating harborage or habitat for beneficial species in an integrated pest management (IPM) plan is not ideal, from a food safety perspective, for controlling rodents which carry disease and use harborage as their habitat. We need to be prepared to make difficult decisions about tradeoffs that may negatively affect food safety, habitat, and our environment.

In this paper we briefly address major impacts of climate change to agriculture (e.g., temperature changes, water shortage, and increased pests), identify the methods of adaptation 
Fig. 1 Table of seasonal vulnerabilities and some potential adaptations to climate change for crops and food animals

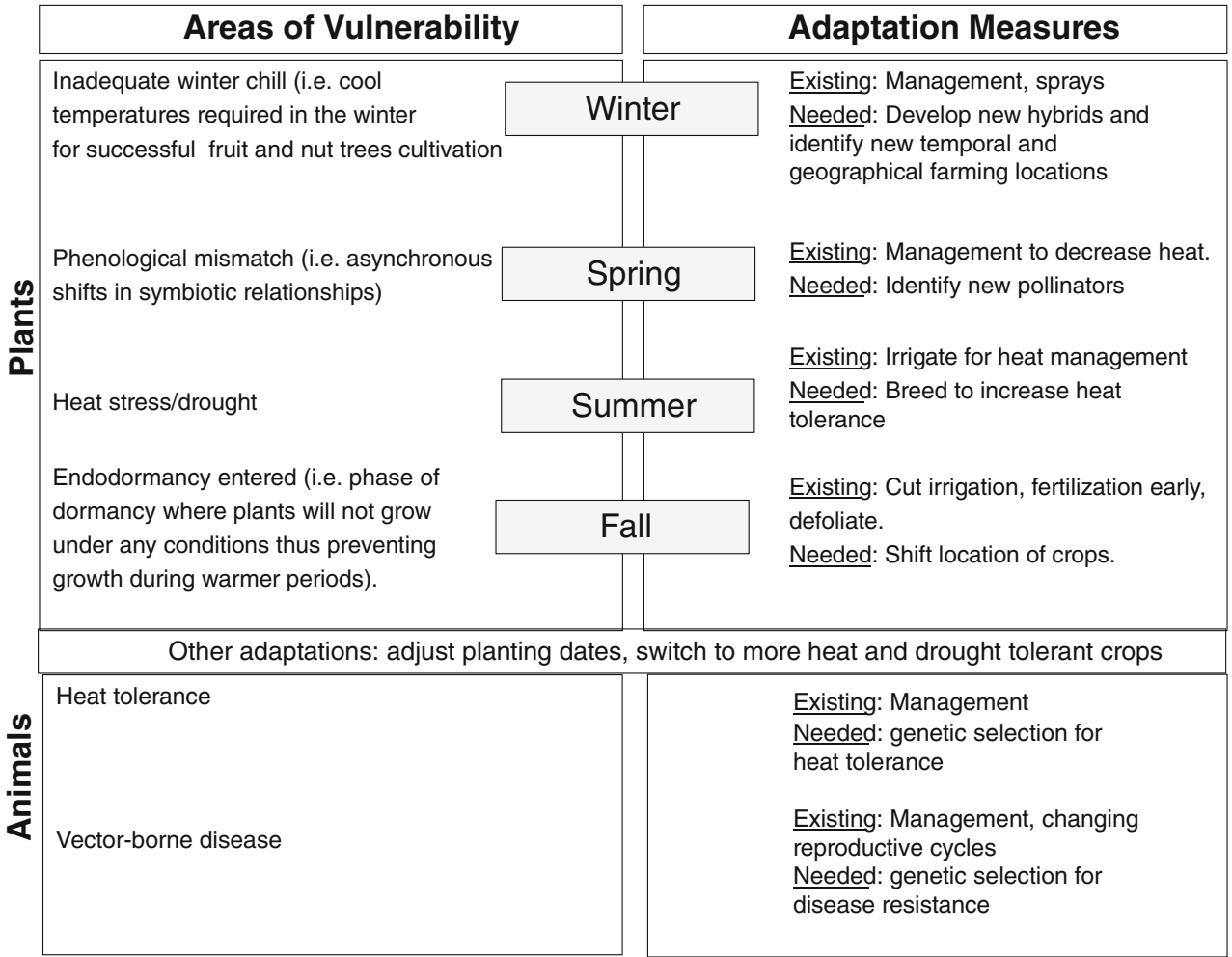

for each of those impacts and, finally, identify scientific and policy challenges associated with each.

\section{Existing Vulnerabilities and Technological Opportunities}

Agriculture's largest vulnerabilities exist in the extreme dependence on a few crops, species of food animals, and select species of pollinators. Currently, approximately 12 crops and 15 mammal and bird species provide approximately 75 and $90 \%$ of our total food and meat supply, respectively [20]. Genetic diversity reduces the potential for cataclysmic plant and food animal failure. Understanding the genome and transcriptome of crops and food animals is essential toward defining vulnerabilities and mitigating/adapting to risk. Application of this knowledge can result in hybrid generation, genetic modifications (GMOs), and synthetic biology, which can be used to improve the response to climate change-associated stressors. These technologies are already being used in order to reduce pesticide use for agricultural crops including socalled Bt (i.e., cloning of insecticidal toxin genes from the bacterium Bacillus thuringiensis into the corn genome) cotton and corn, which have demonstrated higher yields with lower pesticide usage rates than their non-GMO equivalent [21]. Furthermore, similar analysis needs to be conducted on "neglected" plant and animal species that are not widely used for food production in order to identify potential candidate species that can be resilient to changed climate. It is important to recognize that these (i.e., GMOs) types of approaches have potential negative impacts. For example, Bt corn and cotton plants can affect non-target insects [22].

Reliance on pollinator species is essential for both modern and subsidence farming. Due to the potential for phenological mismatching in wild pollinators and colony collapse disorder in honey bees, reliance on pollination is risky. However, because most pollinating plants can be pollinated by an array of species, the potential for adaptation exists. Therefore, new mutualisms need to be identified. Several pollinator studies show higher pollination rates from native pollinators combined with managed pollinators versus $100 \%$ managed honey bee populations $[23,24 \bullet]$.

Other potential vulnerabilities exist in the limited ability to recognize and understand at a more granular level (as opposed to a global level) the regional changes that climate change will have on agricultural production. Weather and climate data from satellite and in situ remote sensing technologies can be used to measure crop yields and gaps in crop yield [25]. Understanding this geography will help us identify new geographical "Goldilocks zones" for current and novel crop cultivation. For example, researchers have identified crops such as almonds thatmay increase in yield, and other crops such as wine grapes and cherries that could decline dramatically with predicted changes in climate [26, 27]. Describing this shift, agronomist Christopher Seifert recently stated for the New Yorker that "by 2050 wheat could be planted rarely in Kansas but widely in Alaska" [28]. Aside from production, how this 
geographical shift in farming will affect storage, transportation, and distribution of food to urban areas is also significant.

\section{Adaptation to Increased Atmospheric $\mathrm{CO}_{2}$ and Temperature for Crops and Livestock}

Although some studies have shown that agricultural production may increase in an environment with greater $\mathrm{CO}_{2}$, crop protein content appears to decrease under such conditions [29]. Bloom and fellow researchers [29] determined the inhibition of nitrates (the most abundant form of nitrogen in agricultural soils) into organic nitrogen in wheat and Arabidopsis. Potential adaptation measures may have to include increasing nitrogen fertilization rates. However, the economic and environmental impacts could be significant. A greater understanding of nitrate assimilation into multiple crops is critical. In addition, plant acclimation (i.e., diminishing of photosynthetic rates over time in a high $\mathrm{CO}_{2}$ environment) is also poorly understood with respect to potential adaptations.

Crops, pollinators, and food animals are sensitive to significant temperature ranges (i.e., minima and maxima). Risks of temperature change to crops in general include altered phenology (timing) of leafing, flowering, harvest, and fruit production, decreased winter chill, asynchrony between flowering and pollinating species, and changes to crop physiology such as plant respiration, photosynthesis, and water use $[6 \bullet, 30,31]$. Globally, data suggest yield increases with mild temperature increases but that temperatures above those levels will significantly decrease crop yields [31]. Expected changes in productivity of corn and soybeans will have a major effect on food animal productivity because they are the major source of feed grains for food animals. Ongoing research includes whole genome sequencing and transcriptional analysis of these major crops. The next challenge is to utilize this information for the rapid development and commercial production of crops that can better withstand climate change, pests, and disease, and have high nutritional value. This is important for major crops and livestock breeds but also for "neglected" crops (crops and breeds of food crops that have been largely ignored by researchers from developed countries because they are not widely used in the west). These types of research may make it easier to identify and develop new varieties of crops that are heat tolerant. From an adaptation perspective it is important to consider breeding of crops resilient to drought and low-chill winters. Due to climate trends in California, the breeding of low-chill fruit tree varieties should be a priority because they are already being impacted by decreased winter chill hours [6॰].

For crops that are sensitive to increases in summer temperatures, including tree and row crops, breeding to increase heat tolerance is essential [32]. In addition, temporal shifts in planting schedules could reduce the effects of heat on production. Specifically, a shift toward earlier planting of annual crops would make for an earlier harvest in the summer, thus avoiding the effects of heat. However, earlier planting would most likely increase the probability of frost damage to seedlings [ $\left.6^{\bullet}\right]$. Other options to consider include intercropping or cover-cropping, which could have a cooling effect by increasing transpiration [6•]. Research is needed to determine which crop combinations could be effective. Management practices that can help crops adapt to increased temperatures should be studied and cataloged as a resource to growers. Some countries have already started to incorporate management practices to adapt to climate change.

In food animal production the negative effect that increased temperature has on production, feed conversion, and reproductive rates has been well-chronicled. For example, rising temperatures in California were found to reduce agricultural production between 7 and $22 \%$ by the end of the century [33].

\section{Adaptation to Water Shortages and Extreme Flooding for Crops and Livestock}

Climate change will affect the magnitude, timing, and frequency of precipitation patterns. The effects of climate change on ET are expected to vary regionally and seasonally. In general, increased temperatures have a positive effect on ET, which can deplete water from soil followed by a decrease in transpiration. During drought conditions the significance of ET is augmented. Because ET contributes to regional water vapor, reduced ET could reduce humidity and the potential for rain. Therefore, developing highly productive and efficient drought-tolerant plants is essential. Currently, there is extensive research on the molecular biology of water stress in plants and breeding drought-tolerant cereal crops (wheat, barley, rice, corn) in terms of yield benefits [34].

Changes in temporal precipitation patterns will in turn affect snow pack and the timing and magnitude of river runoff (increased winter river flow and decreased spring river flow). In short, changes in temperature can have a significant impact on how we currently store water. In California most of the water comes from melted snowpack [6•]. An increase in temperature of $2{ }^{\circ} \mathrm{C}$ would cause significant changes in rain versus snow, and snowmelt timing. Losing the ability to "store" water as snowpack would require many billions of dollars to increase reservoir capacity. From an agricultural perspective, this change in water storage will affect water availability, water quality, and the timing of water application, which is significant because many crops are sensitive to drought during specific development phases [35]. Globally, semi-arid and arid regions are experiencing less precipitation $[6 \bullet]$. With only $5 \%$ of African crops being irrigated, a massive expansion of irrigated farm land in Africa is essential for crop production and food security [36]. The money for the associated costs and infrastructure required to accomplish this currently do not exist. The likelihood of societies and their 
governments re-prioritizing capital infrastructure toward less populated rural areas seems unlikely.

In addition to increased irrigation, accurate real-time and prospective information on climate and soil conditions are essential. Using open-source temperature, moisture, and precipitation data from the National Weather Service and soil data from the United States Geological Service (USGS), entrepreneurial companies are creating sophisticated models in order to increase farming efficiency. This pairing of agronomics, climatology, and Geographic Information Systems (GIS) is essential toward identifying "yield gaps," which allows for the geographical identification of land with the greatest potential for agricultural production [36].

Somewhat counter-intuitively, crop losses due to flooding in the USA ranked second to drought in many of the of the past 12 years [6•]. Because of the likelihood of more extreme weather events with respect to drought and flooding, adaptation strategies should consider options for better management of excess flood waters and rainfall for use, reuse, storage, or groundwater recharge.

Adaptation is ongoing for most agricultural areas. Implementation of water conservation plans, use of water-efficient technologies and improved irrigation uniformity, soil moisture and groundwater monitoring, water budgeting, better management of flood waters, on-farm water storage, groundwater recharge, increasing the water holding capacity of soil and reservoirs, habitat restoration, and field leveling are already occurring [37]. Growers can increase organic matter in the soil (e.g., conservation tillage) to increase water moisture-holding capacity and utilize new technology such as soil moisture sensors, tensiometers, and field-level water meters to track irrigation practices. These conservation measures are essential and will be a critical tool as agriculture adapts to a changing climate with unpredictable water supplies. Recycling water practices on modern dairies (e.g., reusing lagoon water multiple times for flushing free-stalls and then applying as a soil amendment), if done appropriately with respect to food safety and soil and groundwater management, can be an appropriate management adaptation to address water shortages [38].

\section{Adaptation to Increased Insects, Weeds, and Other Diseases, and Impacts of Pollination for Crops and Livestock}

Insects, weeds, parasites, bacteria, and viruses are sensitive to changes in climate. In general, climate change is expected to drive pests, weeds, and pollinator populations to higher elevations and latitudes depending on the species and location $[6 \bullet, 39]$. For example, in California, global warming is predicted to increase the geographical distribution of the pink bollworm (a pest of cotton) to a region that has previously been inhospitable due to heavy frost, and shift the range of the vine mealybug (a pest of grapes) further north [40]. Additionally, increased atmospheric $\mathrm{CO}_{2}$ leads to increased perennial weed root biomass, plant consumption by caterpillars, aphid reproduction rate, and decreased insect development rates, which can alter synchrony with host plants [41, 42]. Less understood is how climate change will affect the ecology of current IPM practices with respect to loss of biological control [43]. The interface between harmful and beneficial insect management is an essential component of IPM associated with the farming of multiple specialty crops. However, predicting how that interface will change as the climate changes is difficult because climate change will affect both the pest (i.e., weed or insect) and the control species [40]. One study showed that for the control of St. John's wort, one species of chrysomelid beetle is more successful in regions of cold winter while another species is better in areas with mild winters [44]. Further research is required to understand these interactions at a regional level.

Conventionally grown monocultures will likely be more vulnerable to pest and pollinator changes. Currently, California averages six new invasive species per year, which are thought to be introduced primarily via trade and travel [6•]. Increased temperatures have the potential to result in the introduction of more invasive species through expanded habitat range and, hence, lead to greater potential destruction [45].

Climate change could dramatically impact pollinators (both insect and avian) by shifting the ranges of plants and insects [8]. Retaining a diversity of pollinators has the potential to confer redundancy and resilience to climate change [24•]. Therefore, an essential adaptation tool is to provide habitat to native pollinators and other beneficials in existing agricultural crop production areas.

Studies show that improved landscape quality increases wild pollinator abundance. Specifically, the highest bee abundances occur on fields that have crop diversity and include some surrounding natural habitats [46]. Cities and counties could begin to incorporate pollinator habitat restoration into their climate action plans. In addition, research is needed for selffertile varieties of some crops, starting with breeding species that are currently completely reliant on pollination, such as almonds.

\section{Reducing Food Wastage}

One other adaptation that should be considered with respect to agricultural efficiency is reducing food wastage. According to the Food and Agricultural Organization (FAO), approximately one third of all food produced for human consumption globally is lost or wasted. According to the same study, this uneaten food occupies $30 \%$ of the world's agricultural land area. Therefore, this wasted food not only represents a "missed opportunity" with respect to calories of food lost but also reflects the environmental impact of this wasted food. 
With the potential for decreased agricultural production associated with climate change, reducing food wastage is essential. In one way the FAO report is good news, in that changes designed to reduce food waste from "farm to fork" could have a major impact on decreasing food wastage. In addition, this is the first global report of its kind and will most likely bring needed attention to the issue of food wastage from farm to fork. Increased urbanization, if done in the context of intelligent urban planning, could help facilitate this. In addition, technology designed to extend the shelf life of fresh fruits and vegetables, including modified atmospheric packaging and biodegradable coatings, need to be considered and further researched. Furthermore, large-scale composting and/or food waste to energy systems could be utilized where appropriate in order to close the "food waste loop."

\section{Implementation of Policy for Adaptation}

In the absence of global and national efforts to address GHGs and address climate change, several US states have actively engaged in activities to address climate change. California is one such state and has adopted mitigation, adaptation, and research strategies to address GHGs and climate change (Fig. 2). Mitigation of GHGs is supported through several policy-level actions, including the California Global Warming
Act (Assembly Bill 32), which will require California via a "cap and trade" system to reduce anthropogenic GHG emissions to 1990 levels by 2020. Revenue generated can be used for research focused on the state's clean energy goals. In addition, California has developed a climate adaptation strategy and reports such as the "Environmental Goals and Policy Report" by the Governor's Office of Planning and Research [47]. Figure 2 shows the many entities involved in this collaborative effort. While California's economy is different than other nations and regions, the figure demonstrates the multiple levels of integration between academia and the Government with respect to mitigation and adaptation.

Given the financial and resource constraints of developing nations with respect to identifying and implementing adaptation protocols regarding climate change, we anticipate severe disturbances in agricultural production as a result of climate change [48]. Interestingly, because of the developed world's reliance on global trade (including global trade associated with agriculture), it is in the developed world's best interest to facilitate agricultural adaptation and/or mitigation. Currently, it appears that the policy of mitigation (i.e., carbon sequestration from agriculture and reducing deforestation) is more often used in the developing world versus adaptation in part because of the tangible economics of carbon offsets [49].

In a holistic sense, managing and adapting to climate change is about mitigating risk. From a policy perspective,

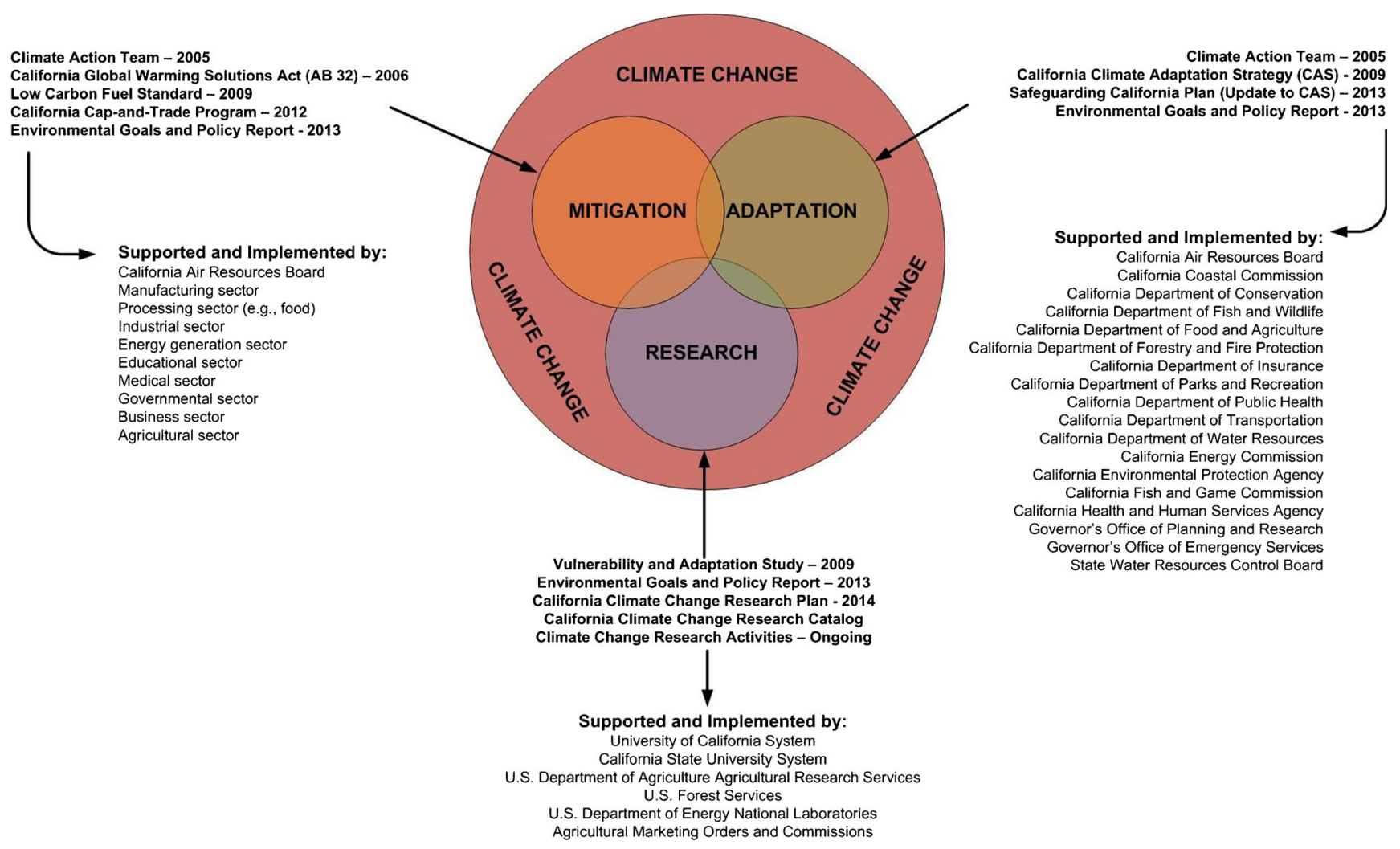

Fig. 2 Use of mitigation, adaptation, and research strategies in California to address climate change. Each of the three strategies are applied through numerous policies and supported and implemented by the different economic sectors, research facilities, and state departments 
our research and adaptation investments should reflect a science-based agenda that prioritizes sustainable food production in an altered climate. A "triage" approach at the global, regional, and local levels could help identify the intersection between the most important plants and animals and the geographical and temporal parameters essential for their optimal productivity. On the basis of this information, modified crops and animals could be grown on land predicted to be successful. In order to accomplish this, multiple tools need to be offered for farmers globally. Perhaps most importantly, farmers need to be engaged and supported in the use of these practices.

\section{Conclusions}

In the coming decades climate change will pose significant challenges on our current agricultural practices from "farm to fork." A "business as usual" approach in the way we grow plants and raise food animals will result in decreased productivity. Increasing urbanization will place challenges on efficient transportation of food and food waste. Adaptation is one approach toward mitigating the effects of climate change on food production. Adapting to climate change will require temporal and spatial shifts in the way we grow crops and raise food animals. Accessible, granular, real-time, and prospective data will allow farmers to utilize resources more efficiently. Appropriate selection and GMO in crops, pollinators, and food animals are essential toward controlling disease and maintaining productivity and nutritional quality. Acknowledgments We thank Mackenzie Johnson for editing this
manuscript.

\section{Compliance with Ethics Guidelines}

Conflict of Interest Maurice Pitesky, Amrith Gunasekara, Carolyn Cook, and Frank Mitloehner have nothing to disclose.

Human and Animal Rights and Informed Consent This article does not contain any studies with human or animal subjects performed by any of the authors.

\section{References}

Papers of particular interest, published recently, have been highlighted as:

- Of importance

1. Johannesen AB, Nielsen A, Skonhoft A. Livestock management at northern latitudes Potential economic effects of climate change in sheep farming. Ecol Econ. 2013;93:239-48.

2. Berkeley, U. Berkeley Earth Surface Temperature 2014 [cited 2014 1/11/2014]; Available from: http://berkeleyearth.lbl.gov/city-list/.
3. Lobell DB et al. Impacts of future climate change on California perennial crop yields: Model projections with climate and crop uncertainties. Agric For Meteorol. 2006;141(2-4):208-18.

4. Baldocchi D, Wong S. Accumulated winter chill is decreasing in the fruit growing regions of California. Clim Chang. 2008;87(1):S153-66.

5. California Department of Food and Agriculture. California Agricultural Resource Directory 2010-2011. Sacramento: California Department of Food and Agriculture; 2011. p. 174.

6. California Department of Food and Agriculture. Climate Change Consortium for Speciality Crops: Impacts and Strategies for Resilance. Sacramento: California Department of Food and Agriculture; 2013. p. 76. This was a comprehensive report from multiple off-site meetings with experts in California agricultural production.

7. Both $\mathrm{C}$ et al. Climate change and unequal phenological changes across four trophic levels: constraints or adaptations? J Anim Ecol. 2009;78(1):73-83.

8. Chen IC et al. Rapid Range Shifts of Species Associated with High Levels of Climate Warming. Science (Washington DC). 2011;333(6045):1024-6.

9. Post E et al. Warming, plant phenology and the spatial dimension of trophic mismatch for large herbivores. Proc R Soc Biol Sci Ser B. 2008;275(1646):2005-13.

10. Klein $\mathrm{AM}$ et al. Importance of pollinators in changing landscapes for world crops. Proc R Soc B-Biol Sci. 2007;274(1608):303-13.

11. Petzoldt, C. and A. Seaman. Climate Change Effects on Insects and Pathogens Climate Change and Agriculture: Promoting Practical and Profitable Responses 2005 [cited 2014 1/13/2014]; Available from: http://www.climateandfarming.org/pdfs/FactSheets/III. 2Insects.Pathogens.pdf.

12. Purse BV et al. Climate change and the recent emergence of bluetongue in Europe. Nat Rev Microbiol. 2005;3(2):171-81.

13. Veldhuis AMB et al. Schmallenberg virus epidemic in the Netherlands: Spatiotemporal introduction in 2011 and seroprevalence in ruminants. Prev Vet Med. 2013;112(1-2):35-47.

14. Gunal M. The effects of early-age thermal manipulation and daily short-term fasting on performance and body temperatures in broiler exposed to heat stress. J Anim Physiol Anim Nutr. 2013;97(5):854-60.

15. Walthall, C.L., J. Hatfield, P. Backlund, L. Lengnick, E. Marshall, M. Walsh, S. Adkins, M. Aillery, E.A. Ainsworth,, et al., Climate Change and Agriculture in the United States: Effects and Adaptation A.R. Service, Editor. 2012: Washington D.C. . p. 186.

16. Bigford, T.E., Scary Numbers. Fisheries (Bethesda), 2013. 38(10).

17. Haden VR et al. Use of local greenhouse gas inventories to prioritise opportunities for climate action planning and voluntary mitigation by agricultural stakeholders in California. J Environ Plan Manag. 2013;56(4):553-71.

18. Penn State College of Earth and Mineral Sciences. From Meteorology to Mitigation: Understanding Global Warming 2013 [cited 2013 12/22/2013]; Available from: https://www.e-education. psu.edu/meteo469/node/175.

19. Mann ME, Kump LR. Dire Predictions Understanding Global Warming: The Illustrated Guide to the findings of the IPCC. New York: DK Publishing; 2008.

20. Harvard School of Public Health. BIodiversity and Food Produciton 2014 [cited 2014 1/15/2014]; Available from: http:// chge.med.harvard.edu/topic/biodiversity-and-food-production.

21. Marra, M., P. Pardey, and J. Alston, The Payoffs to Transgenic Field Crops: An Assessment of the Evidence. Journal of Agrobiotechnology management and economics 5(2).

22. Losey JE, Raylor LS, Carter ME. Transgenic pollen harms monarch larvae. Nature. 1999;399(6733):214.

23. Garibaldi LA et al. Wild Pollinators Enhance Fruit Set of Crops Regardless of Honey Bee Abundance. Science. 2013;339(6127):1608-11. 
24. Brittain C et al. Synergistic effects of non-Apis bees and honey bees for pollination services. Proc R Soc B-Biol Sci. 2013;280(1754):7. This paper demonstrates potential for improving pollinatordependent crop yields in a sustainable manner.

25. Seifert C, Ortiz-Monasterio JI, Lobell DB. Satellite-Based Detection of Salinity and Sodicity Impacts on Wheat Production in the Mexicali Valley. Soil Sci Soc Am J. 2011;75(2):699-707.

26. Lobell DB, Field CB. California perennial crops in a changing climate. Clim Chang. 2011;109(1):317-33.

27. Jackson LE et al. Case study on potential agricultural responses to climate change in a California landscape. Clim Chang. 2011;109(1):407-27.

28. Specter, M., Climate By Numbers in The New Yorker 2013. p. 38-43.

29. Bloom AJ et al. Carbon Dioxide Enrichment Inhibits Nitrate Assimilation in Wheat and Arabidopsis. Science (Washington DC). 2010;328(5980):899-903.

30. Georgescu M, Lobell DB, Field CB. Direct climate effects of perennial bioenergy crops in the United States. Proc Natl Acad Sci U S A. 2011;108(11):4307-12.

31. Schlenker W, Roberts MJ. Nonlinear temperature effects indicate severe damages to US crop yields under climate change. Proc Natl Acad Sci U S A. 2009;106(37):15594-8.

32. Pope $\mathrm{KS}$ et al. Detecting nonlinear response of spring phenology to climate change by Bayesian analysis. Glob Chang Biol. 2013;19(5):1518-25.

33. Hayhoe $\mathrm{K}$ et al. Emissions pathways, climate change, and impacts on California. Proc Natl Acad Sci U S A. 2004;101(34):12422-7.

34. Morison JIL et al. Improving water use in crop production. Philos Trans Royal Soc Lon B Biol Sci. 2008;363(1491):639-58.

35. Mendelsohn R, Nordhaus WD, Shaw D. THE IMPACT OF GLOBAL WARMING ON AGRICULTURE - A RICARDIAN ANALYSIS. Am Econ Rev. 1994;84(4):753-71.

36. Sayer J, Cassman KG. Agricultural innovation to protect the environment. Proc Natl Acad Sci U S A. 2013;110(21):8345-8.

37. Gleick PH, Christian-Smith J, Cooley H. Water-use efficiency and productivity: rethinking the basin approach. Water Int. 2011;36(7): 784-98.
38. Bradford SA et al. Reuse of concentrated animal feeding operation wastewater on agricultural lands. J Environ Qual. 2008;37(5):S97-115.

39. Bradley BA, Wilcove DS, Oppenheimer M. Climate change increases risk of plant invasion in the Eastern United States. Biol Invasions. 2010;12(6):1855-72.

40. Gutierrez AP et al. Prospective evaluation of the biological control of vine mealybug: refuge effects and climate. J Appl Ecol. 2008;45(2):524-36.

41. Coviella CE, Trumble JT. Effects of elevated atmospheric carbon dioxide on insect-plant interactions. Conserv Biol. 1999;13(4):700-12.

42. Ziska LH, Faulkner S, Lydon J. Changes in biomass and root: shoot ratio of field-grown Canada thistle (Cirsium arvense), a noxious, invasive weed, with elevated $\mathrm{CO} 2$ : implications for control with glyphosate. Weed Sci. 2004;52(4):584-8.

43. Hance, T., et al., Impact of extreme temperatures on parasitoids in a climate change perspective, in Annual Review of Entomology. 2007, Annual Reviews: Palo Alto. p. 107-126.

44. Schops K, Syrett P, Emberson RM. Summer diapause in Chrysolina hyperici and C-quadrigemina (Coleoptera: Chrysomelidae) in relation to biological control of St John's wort, Hypericum perforatum (Clusiaceae). Bull Entomol Res. 1996;86(5):591-7.

45. Butler CD, Trumble JT. The potato psyllid, Bactericera cockerelli (Sulc) (Hemiptera: Triozidae): life history, relationship to plant diseases, and management strategies. Terrestrial Arthropod Rev. 2012;5(2):87-111.

46. Kennedy $\mathrm{CM}$ et al. A global quantitative synthesis of local and landscape effects on wild bee pollinators in agroecosystems. Ecol Lett. 2013;16(5):584-99.

47. Agency, C.N.R., 209 California Climate Adaptation Strategy 2009, State of Califonria p. 146.

48. Paustian K. Bridging the data gap: engaging developing country farmers in greenhouse gas accounting. Environ Res Lett. 2013;8(2):1-5.

49. Hussein, Z., Climate change mitigation policies and poverty in developing countries. Environmental Research Letters, 2013. 8(3). 